\title{
Long-term prognostic significance of late gadolinium enhancement in non-ischemic dilated cardiomyopathy: further evidence from 184 patients
}

\author{
Stephanie Lehrke*, Michael Schöb, Henning Steen, Helmut Kemmling, \\ Dirk Lossnitzer, Philipp Ehlermann, Constanze Merten, \\ Grigorius Korosoglou, Evangelos Giannitsis and Hugo A Katus
}

Address: Medizinische Universitätsklinik Heidelberg, Heidelberg, Germany

* Corresponding author

from 13th Annual SCMR Scientific Sessions

Phoenix, AZ, USA. 2I-24 January 2010

Published: 21 January 2010

Journal of Cardiovascular Magnetic Resonance 2010, I2(Suppl I):O8 doi:I0.I 186/I532-429X-I2-SI-O8

This abstract is available from: http://jcmr-online.com/content//2/SI/O8

(C) 2010 Lehrke et al; licensee BioMed Central Ltd.

\section{Introduction}

Non-ischemic dilated cardiomyopathy (DCM) is a major cause for cardiovascular morbidity and premature mortality. Due to the variable clinical course, risk stratification is of paramount importance in these patients to identify those most likely to benefit from aggressive treatment strategies. There is emerging evidence for the prognostic significance of late gadolinium enhancement (LGE) in patients with DCM.

\section{Objective}

The goal of this study was to further investigate the longterm prognostic significance of LGE in a large cohort of patients with DCM presenting to a tertiary referral center.

\section{Methods}

Contrast-enhanced cardiovascular magnetic resonance (CE-CMR) was performed in 184 consecutive patients with DCM on a $1.5 \mathrm{~T}$ clinical scanner. Significant coronary artery disease had been ruled out in all patients. LV volumes and mass were derived from SSFP cine images. Presence of LGE was determined by two independent observers. Patients were followed for the primary endpoint of cardiac death and a composite endpoint of cardiac death, hospitalization for decompensated heart failure or appropriate ICD firing for a mean of $685 \pm 30$ days.

\section{Results}

LGE was detected in 72/184 patients (39\%). Patients with LGE showed a higher NYHA classification $(2.2 \pm 0.09$ vs. $1.9 \pm 0.07, \mathrm{p}=0.02)$ and were more often on oral diuretics (42/72 pts. vs. $45 / 112$ pts., $\mathrm{p}=0.02)$. Presence of LGE was associated with a lower EF $(31.6 \pm 1.7 \%$ vs. $40.4 \pm 1.2 \%$, $\mathrm{p}<0.001)$, higher EDV $(288.7 \pm 12.2 \mathrm{ml}$ vs. $233.6 \mathrm{ml}, \mathrm{p}<$

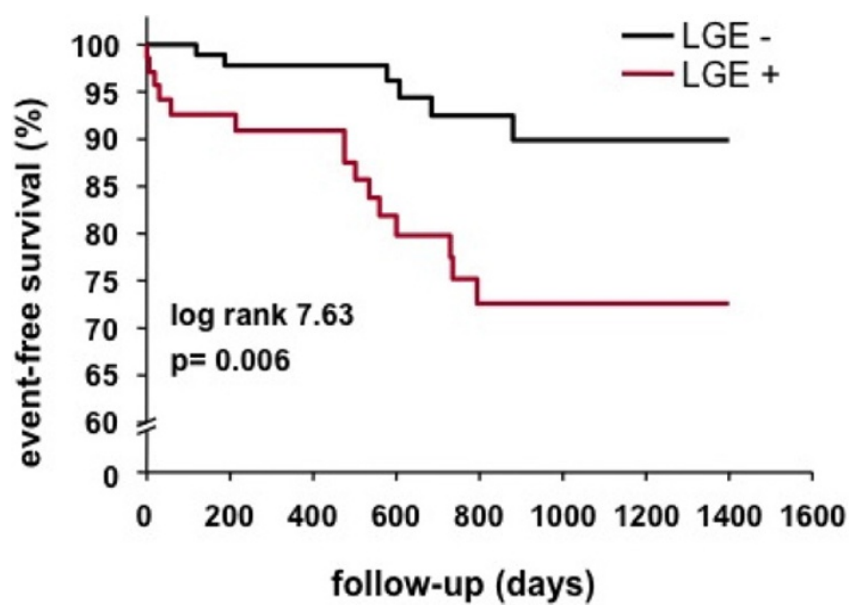

Figure I

Event-free survival according to presence of LGE. 
Table I: Predictors of the composite endpoint by Cox regression

\begin{tabular}{lll}
\hline & HR (95\% Cl) & $P$ \\
\hline Univariate & & \\
\hline EF (\%) & $0.94(0.91-0.98)$ & $<0.001$ \\
LGE (y/n) & $3.5(1.4-9)$ & 0.01 \\
Age (yrs) & $1.06(1.02-1.09)$ & 0.001 \\
Male gender & $1.29(0.43-3.83)$ & 0.65 \\
NYHA class & $1.84(0.98-3.46)$ & 0.06 \\
\hline Multivariate model & & \\
\hline Age (yrs) & & \\
EF (\%) & $1.04(1.02-1.09)$ & 0.001 \\
\hline
\end{tabular}

$0.001)$ and a more pronounced increase of LV mass/BSA $\left(81.9 \pm 2.9 \mathrm{~g} / \mathrm{m}^{2}\right.$ vs. $\left.70 \pm 2.2 \mathrm{~g} / \mathrm{m}^{2}, \mathrm{p}<0.001\right)$. There was a trend towards a higher incidence of the primary endpoint in patients with LGE $(4 / 72$ vs. $1 / 112, p=0.06)$. The rate of the composite endpoint was significantly associated with the presence of LGE (15/72 vs. 6/112, p = 0.002, Figure 1). When entered into multivariate Cox regression analysis, LGE did not retain an independent predictive value (Table 1).
Publish with Bio Med Central and every scientist can read your work free of charge

"BioMed Central will be the most significant development for disseminating the results of biomedical research in our lifetime. " Sir Paul Nurse, Cancer Research UK

Your research papers will be:

- available free of charge to the entire biomedical community

- peer reviewed and published immediately upon acceptance

- cited in PubMed and archived on PubMed Central

- yours - you keep the copyright

Submit your manuscript here:

http://www.biomedcentral.com/info/publishing_adv.asp 